\title{
MODEL-BASED CONCEPT FOR SCHEDULING ANALYSIS OF PACKAGING LINES
}

\author{
Ilya Kukushkin ${ }^{\mathrm{a}, \mathrm{b}}$, Alina Zavrazhina ${ }^{\mathrm{c}}$, Johann Grabenweger ${ }^{\mathrm{b}}$, Branko Katalinic ${ }^{\mathrm{a}}$, \\ Askar Kildibekov ${ }^{\mathrm{c}}$, Damir Haskovic ${ }^{\mathrm{a}}$
}

${ }^{a}$ Vienna University of Technology, Karlsplatz 13/311, 1040 Vienna, Austria

${ }^{b} \mathrm{KHS}$ GmbH, Planiger Strasse 139, Bad Kreuznach, Germany

'Omsk State Transport University, Karl Marx Ave. 35, Omsk 644046, Russia

\begin{abstract}
Modern trends in beverage industry are characterized by higher product variety and its shorter lifetime. The producer needs to react faster and adapt his production strategy to the changing demand. Scheduling optimization is one of the most successful strategies to manage these changes. Development of IT concepts allows to model the scheduling and find optimal production strategies with relatively simple simulation tools. This paper discusses a new concept for scheduling analysis of filling and packaging lines using the simulation modeling. The model simulates the production of filling and packaging line for PET bottles. This paper focuses on the description of the main steps and methods for developing the simulation model, automatic key performance indicators calculation and the experiment of the overall equipment effectiveness (OEE) analysis. This includes the OEE dependence on the number of changeovers within the line.
\end{abstract}

Keywords: sheduling; discrete-event simulation; agent-based simulation; filling and packaging; industry 4.0; anylogic
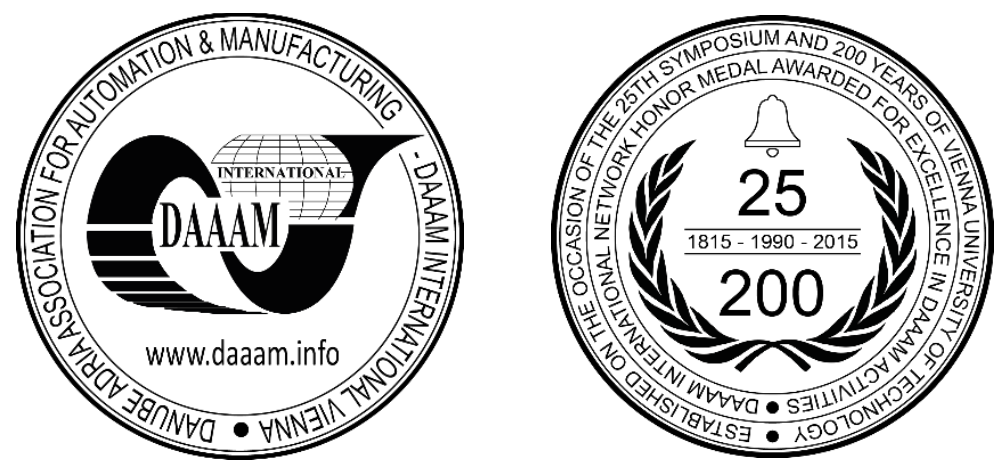

This Publication has to be referred as: Kukushkin, I[lya]; Zavrazhina, A[lina]; Grabenweger, J[ohann]; Kildibekov, A[skar]; Katalinic, B[ranko] \& Haskovic, D[amir] (2016). Model-based concept for scheduling analysis of packaging lines, Proceedings of the 26th DAAAM International Symposium, pp.1149-1157, B. Katalinic (Ed.), Published by DAAAM International, ISBN 978-3-902734-07-5, ISSN 1726-9679, Vienna, Austria

DOI: $10.2507 / 26$ th.daaam.proceedings.162 


\section{Introduction}

The beginning of 21 st century is characterized with a rapid development of science and technology. The significant difference in development rate of different fields is observable. The ideas, results and concepts from

\begin{tabular}{|ll|}
\hline Nomenclature \\
PLE & Planning efficiency \\
$\mathrm{A}$ & Availability \\
$\mathrm{PE}$ & Performance efficiency \\
$\mathrm{RQ}$ & Rate of quality \\
$\mathrm{t}_{\mathrm{L}}$ & Loading time, min \\
$\mathrm{t}_{\mathrm{TP}}$ & Theoretical production time, min \\
$\mathrm{t}_{\mathrm{O}}$ & Operating time, min \\
$\mathrm{t}_{\mathrm{L}}$ & Loading time, min \\
$\mathrm{t}_{\mathrm{NO}}$ & Net operating time, min \\
$\mathrm{t}_{\mathrm{VO}}$ & Valuable operating time, min \\
$\mathrm{N}$ & Number of good packages, pieces \\
$\mathrm{t}_{\mathrm{TP}}$ & Theoretical production time, min \\
$\mathrm{NO}$ & Nominal output, pieces/min \\
$\mathrm{N}_{1}$ & Number of good packages, produced before changeover, pieces \\
$\mathrm{N}_{2}$ & Number of good packages, produced after changeover, pieces \\
$\mathrm{t}_{\mathrm{TP} 1}$ & Theoretical production time before changeover, min \\
$\mathrm{t}_{\mathrm{TP} 1}$ & Theoretical production time after changeover, min \\
$\mathrm{NO}_{1}$ & Nominal output before changeover, pieces/min \\
$\mathrm{NO}_{2}$ & Nominal output after changeover, pieces/min \\
& \\
\hline
\end{tabular}

faster and more successfully developed fields disseminate to all the others. Development of modern industry is strongly supported by the progress of information technology. This developing trend has a target to build a new kind of industry, generally known as Industry 4.0 [1].

The suggested principles are used by companies in developing of Industry 4.0 pilots. The list and description of the design principles Industry 4.0 is shown in Table 1 [2].

\begin{tabular}{ll}
\hline Name & \multicolumn{1}{c}{ Description } \\
\hline Interoperability & $\begin{array}{l}\text { The ability of companies, cyber-physical systems and humans communicate with each } \\
\text { other by means of Internet of Things and the Internet of Services. }\end{array}$ \\
Virtualization & $\begin{array}{l}\text { Creating a virtual copy of the Smart Factory. The simulation model and the virtual plant } \\
\text { models linked to the sensor Data. In case of need various kinds of information can be } \\
\text { extracted by using model. }\end{array}$ \\
The ability of cyber-physical systems to make decisions on their own. Machines are \\
notified of next working steps. \\
Deala collection and analysis in real time. \\
Service Orientation \\
$\begin{array}{l}\text { Access to services companies, cyber-physical systems and humans via the Internet of } \\
\text { Services. The particular product can be constructed based on customer requirements. }\end{array}$ \\
Systems consisting of modules are capable of configurations and module replacement \\
depending on the changed product characteristics
\end{tabular}

Table 1. Description of the design principles Industry 4.0.

Industry 4.0 influences further development of production systems. The efficiency of these systems depends directly on the machines productivity, system control and scheduling strategies. The trend is focused on four main improvements: increase of system flexibility and intelligence, self organization [3], cloud technologies [4] and their implementation [5].

Classical example of production system is a filling and packaging plant. It is organized with the use of machines, automatic production lines and auxiliary equipment. Basic obligations of line operators are immediate reaction on disturbances, process control, maintenance and changeover of equipment.

Modern plant is a complicated object, which is characterized by interrelated dynamic events. Manual plant scheduling usually relies on operator's intuition and past experience. Simple excel-based spreadsheets are not flexible enough to solve complicated scheduling problems. Modern computing resources make possible the creation of factory simulation model and conducting experiments on scheduling optimization. The results of this optimization could help 
system operators in their daily business. This work is the part of IMS group research (Vienna UT), which is focused on the development of Intelligent Advisor Module for system operators [6]. This paper focuses on virtualization in the field of production scheduling for the soft drinks filling and packaging line.

\section{Description of the production line}

The initial model is developed for soft drinks filling and packaging line. The line can be configured to work with 1.5 and 0.5 -liter PET bottles. In both cases the bottles are blown from preforms directly in the line. The production line represents a number of machines connected with each other through conveyors. List of machines and description of their functions are shown in Table 2.

\begin{tabular}{ll}
\hline Machine & Function \\
\hline Blowing machine & Intended for the production of plastic bottles by blowing them out preforms. \\
Filling machine & Fills the beverage into the empty bottles and close them with a cap. \\
Labeling machine & Pastes the label on the bottle filled with beverage. The quality of gluing is checked. \\
Packing machine & Packs bottles in secondary package for instance six-pack or different packaging. \\
Handle application machine & Attaches the handle to the package for easy carrying bottles. \\
Palletizing machine & Combination of robot grouping station and the palletizing station, which forms full pallet. \\
Pallet wrapper & Tightens the pallet with a protective foil. \\
\hline
\end{tabular}

Table 2. Description of the function machines.

Line is formed in 2-block design, which means that the blowing and filling machines are interconnected in one block. The only accumulation table is located between filling and labeling machines, as shown in Fig.1. Other conveyors are not designed for additional accumulation.

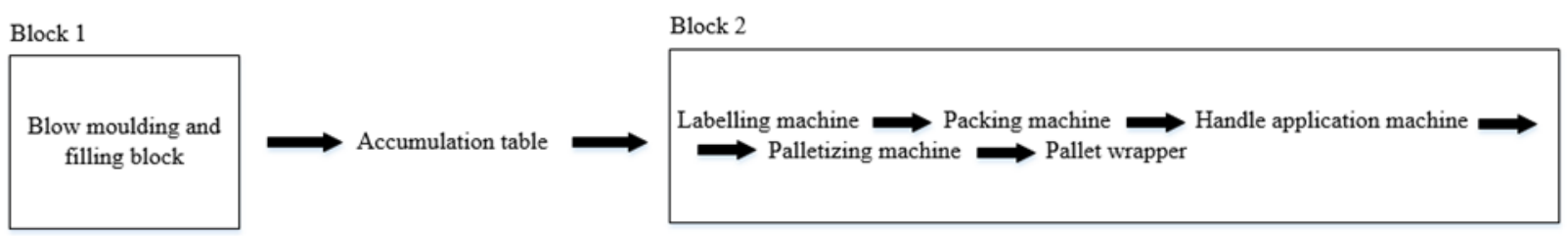

Fig. 1 - 2-block design

The input information about orders contains following fields:

- $\quad$ Beverage Sort type (Cola, Cola light, carbonated water etc)

- Bottle volume, 1

- Lot size, bottle

- type of label

- CIP matrix including cleaning time before the order and cleaning time after the order, sec

- Changeover matrix including changeover time before and after the order, sec

\section{Model development}

Simulation model is designed with the help of Anylogic software. This program allows to solve problems in various fields of modeling: discrete event, system dynamics and agent based modeling. The main difference of AnyLogic from other existing solutions is the ability to combine and simultaneously use different modeling paradigms in the development of one model. It allows to create complex models, which are most compatible with the real production. Developed model uses two simulation methods - agent-based and discrete-event modeling. Discrete-event simulation allows to observe the processes occurring at the production line and agent-based modeling - to set up machine behavior logic.

\subsection{Simulation of machine behavior}

Machine behavior is determined by its active state. The state model is based on Weihenstephan 2005 Standard, developed by TU Munich. The basic tags are the program tag (00200) and the state tag (00300), which are described in [7].

The states are divided into the state groups, as it is shown in Table 3. 


\begin{tabular}{ll}
\hline State Group & Weihenstephan state \\
\hline Operating & Operating \\
Intermediate & Stopping, aborting, holding \\
Machine Stops & Prepared, equipment failure \\
Line-caused stops & Lack, tailback, suspended \\
Operator-caused stops & Emergency stop, held, idle \\
Line-exterior stops & External failure \\
\hline
\end{tabular}

Table 3. Grouped Table of Weihenstephan states within normal production program.

In operating group the machine is functioning as intended. In intermediate group machine is not yet initialized or ready to carry out its intended function.

Machine stops group is active when the production stop is caused by internal machine faults. Line-caused stops group includes the stops caused by lack and tailback.

Operator-caused stops happen when the machine is stopped by the operator. A failure which is not attributable to the machine but which nonetheless leads to a machine stop are typical for line-exterior stops. Example of such stop could be a power cut off.

\subsection{Agent-based part of simulation}

Statechart is used to describe the behavior of machines in Anylogic software. It allows to define the machine states and the transitions between them graphically. Fig. 2. shows the machine statechart, which models the machine behavior. If the machine is able to switch from one state to the other, both of these states will be connected by transition. The transition may be performed in a few cases. For example, upon time-out, if the condition is fulfilled or if statechart receives a message.

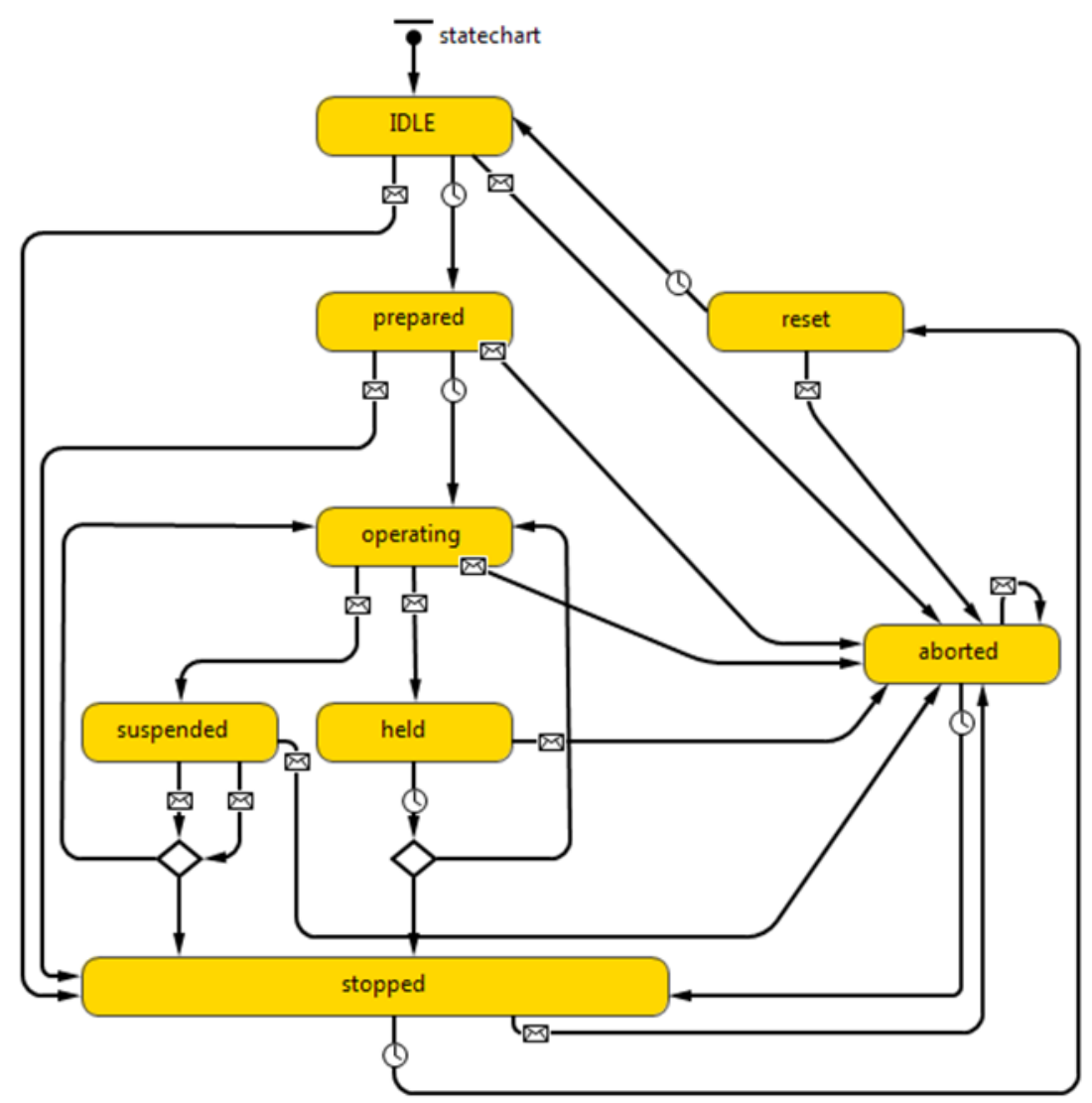

Fig. 2 - Machine statechart in Anylogic software

\subsection{Discrete-event part of simulation}

Function performed by the machine can be divided into a few simple steps. Each of these operations are easily accomplished using the standard library AnyLogic «Enterprise Library objects». 
Packing machine is considered as a further example. The machine combines bottles into the six-packs, which are moved along the conveyor. The machine functions realization is shown in Fig. 3.

The Batch Block forms bottle of parties in the amount of 6 pieces. The Queue block allows to collect statistics. The Conveyor block performs the conveyor function. The conveyor capacity could be flexibly defined in the block properties. When the bottle reached the machine entrance, it can be locked or opened. This operation is performed by the Hold block. Simulation of the packaging operation is carried out by the Delay block.

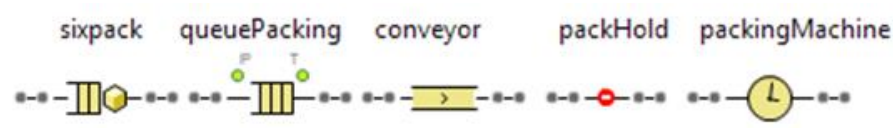

Fig. 3 - Packing machine in the form of blocks

The model includes the quality check blocks, with a possibility to reject the defective bottles. This function is realized with the Recycling block. The Event element is used for the simulation of production events. The model includes several events, based on WS2005 Program and State tags, such as:

- Maintenance - machines maintenance and service work

- Changeover - changeover of the production from 1.5-liter bottles on the 0.5-liter bottles and vice versa

- Cleaning - cleaning machines and other equipment

- Reaction to the occurrence of Lack. In this case, the machine must be converted into the condition «suspended». The machine will stay in this state until its input will not receive new bottle. Thereafter, the machine returns to the state «operating».

- Reaction to occurrence of Tailback. In this case, the input of the machine is locked and the machine is converted to the state «suspended». Input of the machine will be opened when the buffer of next machine will cease to be filled.

- Equipment Failure

- External Failure

- Emergency Stop

- $\quad$ Product lack, if the product tank is empty.

Developed scheme for the whole line is shown in Fig. 4. Blocks include main machine functions and the conveyors between them. Accumulation table is realized with the Queue function.

\subsection{OEE as optimality criterion}

Key Performance Indicators (KPIs) are used to evaluate a various activities results within the organization. They also help to evaluate the performance of departments and employees.

There are many different ways to assess the line performance. One of the most spread KPI for monitoring and improving production efficiency in the industry is OEE - overall equipment effectiveness. Different scholars introduce a number of OEE definitions. In [8] OEE is specified as "a hierarchy of metrics which evaluates and indicates how effectively a manufacturing operation is utilized. The results are stated in a generic form which allows comparison between manufacturing units in different industries. It is not however an absolute measure and is best used to identify scope for process performance improvement, and how to get the improvement».

OEE is often associated with the notion of performance. However, the performance is not the only part of it. All elements used for calculating the OEE listed below [9]:

- Availability (A). Availability is the ratio between the production time and the scheduled production time.

- Performance (P). Performance is the ratio between the factual amount of units produced and the planned number of units produced.

- Quality (Q). Quality is the ratio between the number of good units produced and the total number of units started.

In the model OEE will be calculated in two ways. Formulas for OEE1 calculating are given below [7]:

$$
\begin{aligned}
& \mathrm{OEE}_{1}=\mathrm{PLE} \cdot \mathrm{A} \cdot \mathrm{PE} \cdot \mathrm{RQ} \\
& \mathrm{PLE}=\mathrm{t}_{\mathrm{L}} / \mathrm{t}_{\mathrm{TP}} \\
& \mathrm{A}=\mathrm{t}_{\mathrm{O}} / \mathrm{t}_{\mathrm{L}} \\
& \mathrm{PE}=\mathrm{t}_{\mathrm{NO}} / \mathrm{t}_{\mathrm{O}} \\
& \mathrm{RQ}=\mathrm{t}_{\mathrm{VO}} / \mathrm{t}_{\mathrm{NO}}
\end{aligned}
$$

$\mathrm{OEE}_{2}$ is calculated by the formula:

$$
\mathrm{OEE}_{2}=\mathrm{N} /\left(\mathrm{t}_{\mathrm{TP}} \cdot \mathrm{NO}\right)
$$


Nominal output depends on the bottle volume.

The formula 7 assumes a different form in the event of changeover:

$$
\mathrm{OEE}_{3}=\left(\mathrm{N}_{1}+\mathrm{N}_{2}\right) /\left(\mathrm{t}_{\mathrm{TP} 1} \cdot \mathrm{NO}_{1}+\mathrm{t}_{\mathrm{TP} 2} \cdot \mathrm{NO}_{2}\right)
$$

$\mathrm{OEE}_{1}$ and $\mathrm{OEE}_{2}$ must be the same in one week.

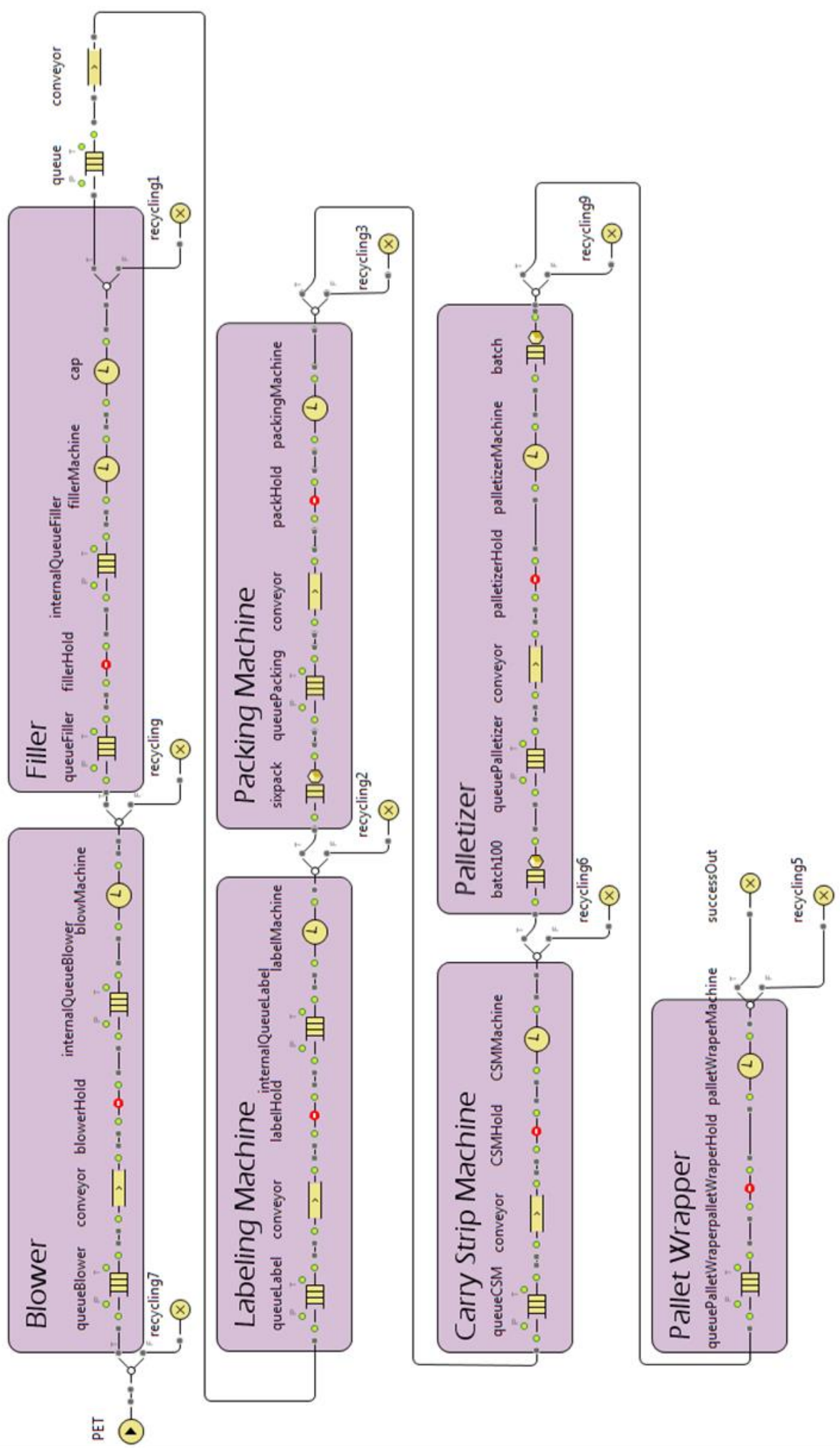

Fig. 4 - Filling and packaging line in Anylogic software 


\section{Experiments}

The experiment goal is to visualise the OEE changes under the influence of changeover. Five experiments were conducted in order to identify the impact of the number of changeovers in the OEE. The first experiment is conditioned by one changeover per week. In the next experiments the number of changeovers is increased by 1 , so that is in second experiment 2 changeovers are conducted, in third - 3 and so on. The dependence of the OEE on the number of changeovers for each experiment is shown in Fig. 5-9.

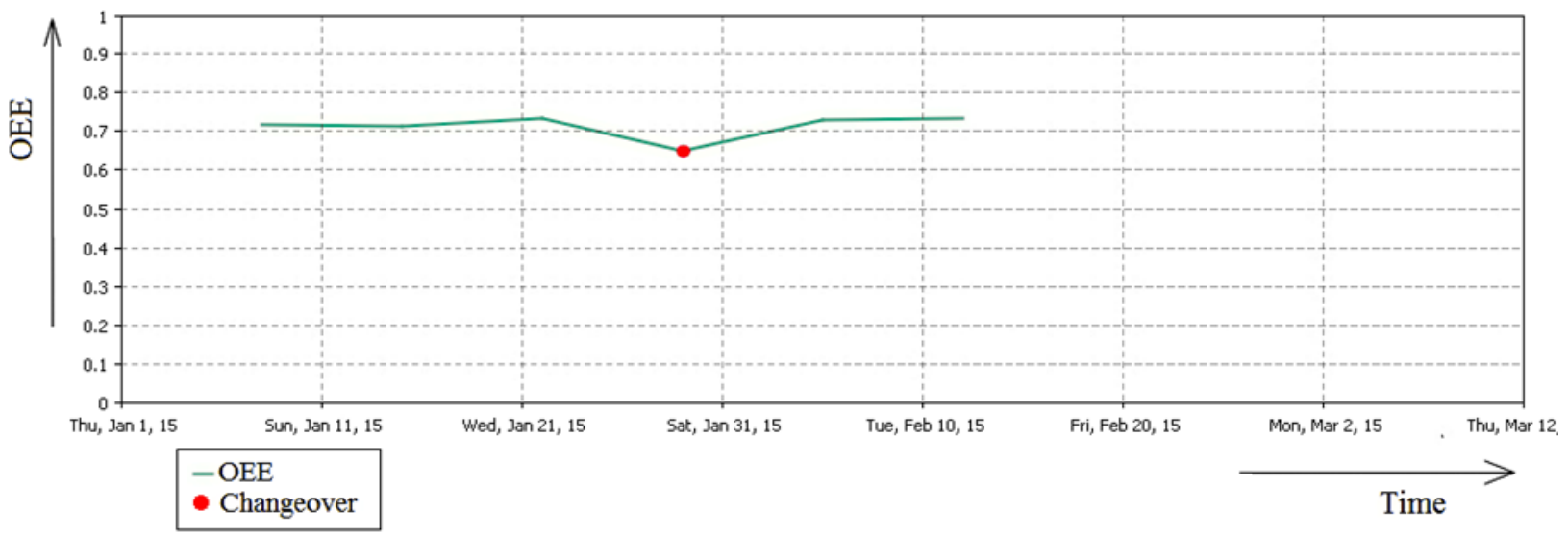

Fig. 5 - The dependence of the OEE on the number of changeovers in the first experiment

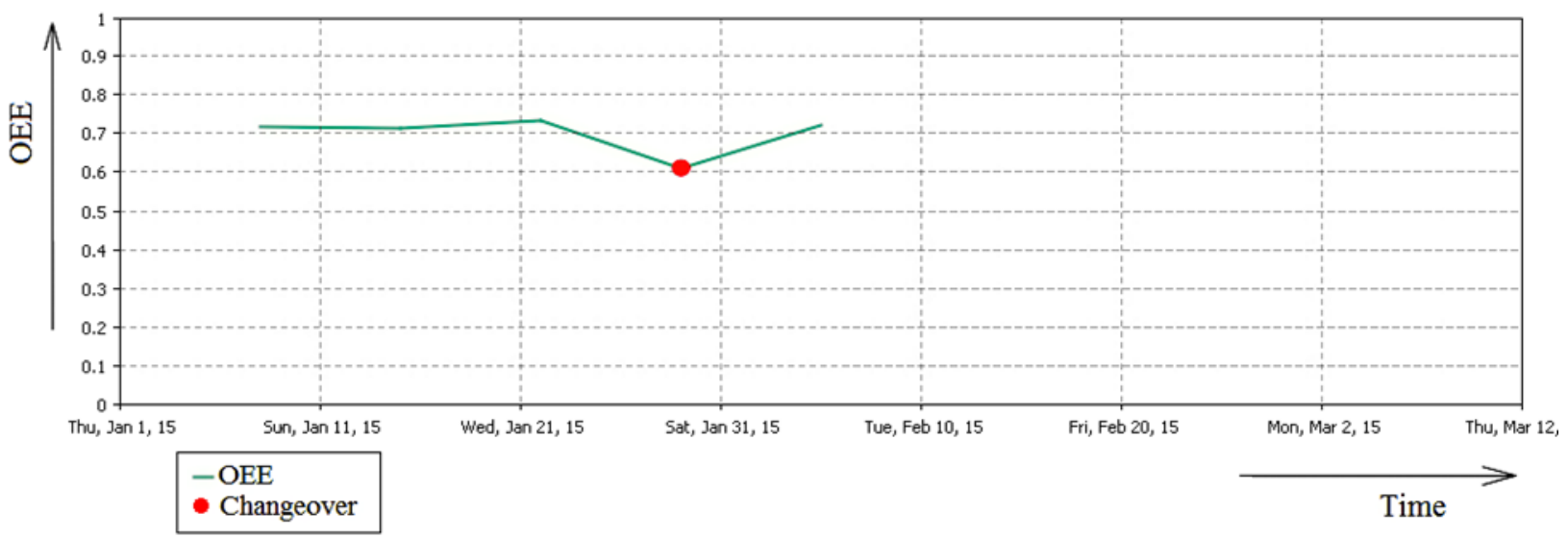

Fig. 6 - The dependence of the OEE on the number of changeovers in the second experiment

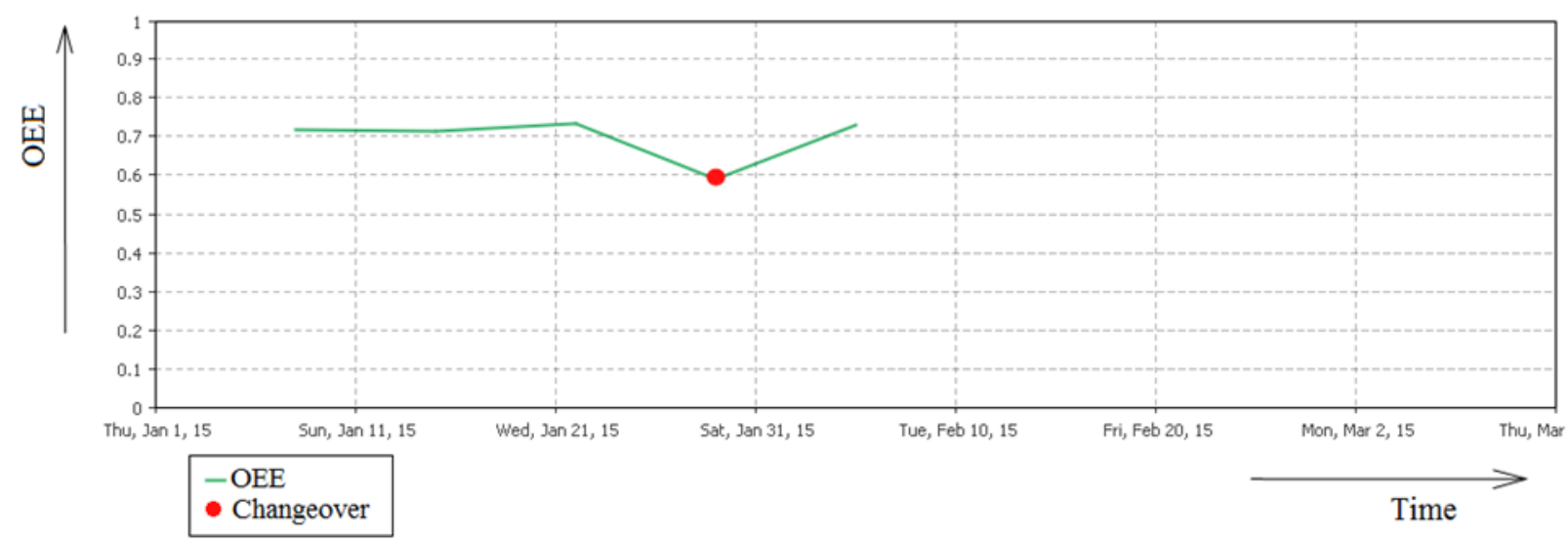

Fig. 7 - The dependence of the OEE on the number of changeovers in the third experiment 


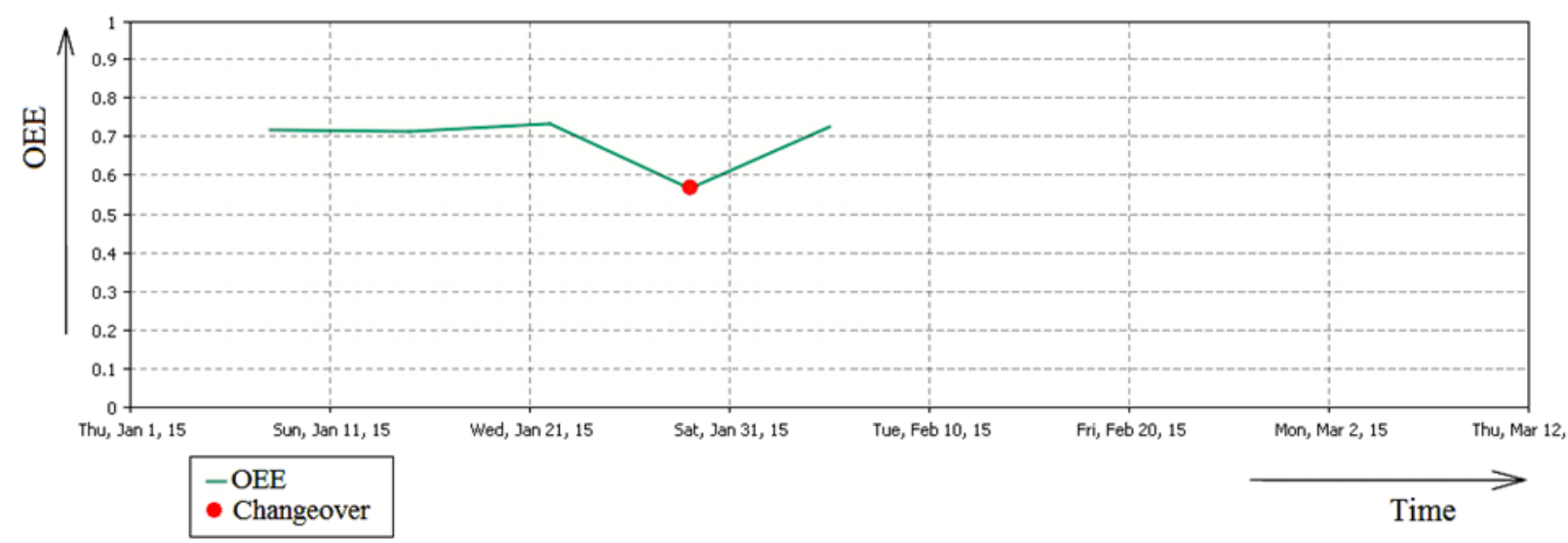

Fig. 8 - The dependence of the OEE on the number of changeovers in the fourth experiment

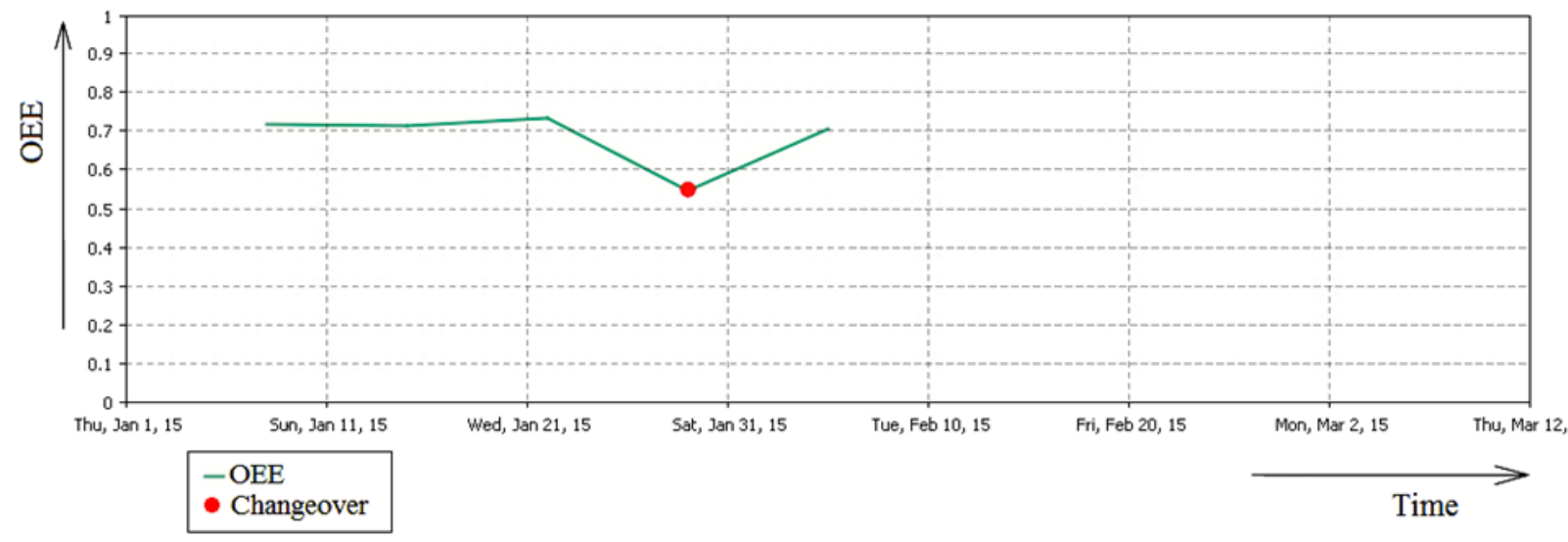

Fig. 9 - The dependence of the OEE on the number of changeovers in the fifth experiment

With the use of the Gantt chart the user gets possibility of visual control of the line due to display information about the status of each machine. Gantt Chart view is shown in Fig. 10.

\section{Gannt Chart}
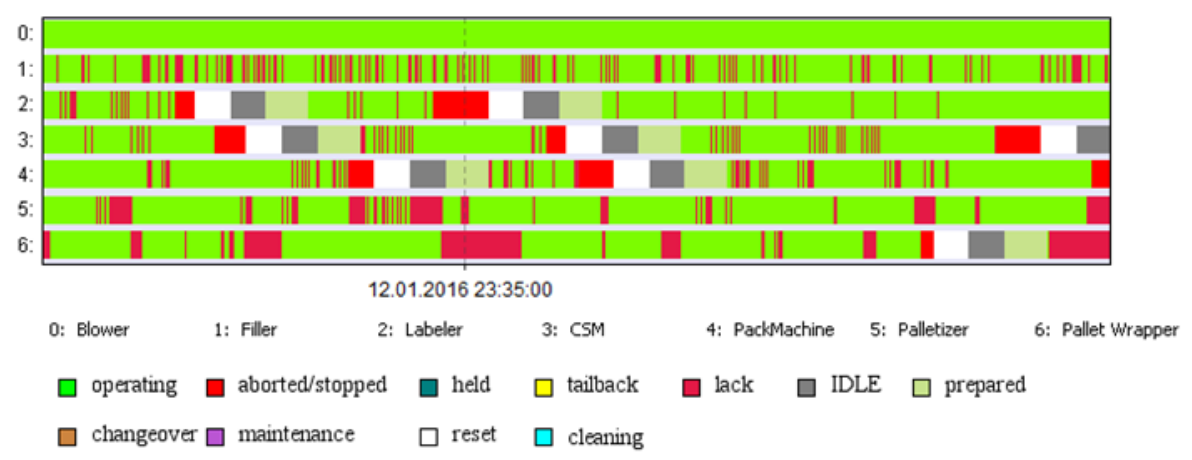

\section{Conclusion}

Fig. 10 - Gantt Chart view

Modern filling plant is a complicated object, which is characterized by interrelated dynamic events. Therefore, its production scheduling is a time and resource consuming task. Scheduling is one of the most important factors affecting line performance.

Optimal scheduling must also include other factors, such as the criteria of energy consumption, warehouse capacity, changeovers, product shelf life, machines dynamic behavior and many others.

This paper describes the main steps and methods of developing the simulation model, automatic key performance indicators calculation and the experiment of the overall equipment effectiveness visualization. This includes the analysis 
of OEE dependence on the number of changeovers. Developed model allows to analyze the line scheduling and to find optimal production strategies using relatively simple simulation tools.

The model is applicable for the complex systems analysis as it performs the assessment of mutual influence of multiple factors on the production process. This assessment could only be performed with the simulation modeling approach.

Future research will be focused on the deeper production analysis and OEE calculations for the practical industrial tasks. Another task will be to introduce the additional planning criteria for the existing model.

\section{References}

[1] Post, P. "Smart Systems for Intelligent Manufacturing - Industry 4.0" Plenary Lecture, 25th DAAAM Symposium, Vienna, Austria, 2014

[2] Hermann, Pentek. Design Principles for Industrie 4.0 Scenarios. 2015. pp:11-13.

[3] Kukushkin , I. K. , Katalinic , B. , Cesarec , P. and Kettler , R. (2011) Reconfiguration in self-organizing systems. Annals of DAAAM for 2011 \& Proceedings of the 22nd International DAAAM Symposium "Intelligent Manufacturing \& Automation: Power of Knowledge and Creativity", Editor B.[ranko] Katalinic, ISSN 1726-9679, ISBN 978-3-901509-83-4, pp 641-642, Vienna, Austria, Published by DAAAM International, Vienna, 2011

[4] Katalinic, B., Kukushkin, I., Pryanichnikov, V., \& Haskovic, D. (2014). Cloud Communication Concept for Bionic Assembly System, Procedia Engineering, Volume 69, 2014, Pages 1562-1568, ISSN 1877-7058, doi:10.1016/j.proeng.2014.03.156

[5] Katalinic, B., Kukushkin, I., \& Haskovic, D. Bionic Assembly System Cloud: Functions, Information Flow and Behavior, 9th International Conference of DAAAM Baltic, Industrial Engineering, ISBN 978-9949-23-620-6, ISSN 2346-6138, pp 103 - 108, ed. T. Otto, Tallinn, Estonia, 2014

[6] Haskovic, D., Katalinic, B., Kukushkin, I. (2014), Role of the Adviser Module in the Hybrid Assembly Subordinating Control Structure, Procedia Engineering, Volume 100, 2015, Pages 1706-1713, ISSN 1877-7058, http://dx.doi.org/10.1016/j.proeng.2015.01.546.

[7] Kather, A. (2009). Fehlerlokalisierung in verketteten Produktionslinien am Beispiel von Lebensmittelverpackungsanlagen (Fault detection in connected production lines on food packaging systems example), Doctoral dissertation, Doctoral Thesis, Technische Universität München

[8] Guide for: Operations Management / Cram101 Textbook Reviews. 2012. 89 p.

[9] OEE for Operators: Overall Equipment Effectiveness / Productivity Development Team. Productivity Press. 1999. $96 \mathrm{p}$.

[10] DIN 8743 German Institute for Standardization: packaging machines and packaging installations, time related definitions, reference factors and calculation fundamentals, 2014. 26 p. 